\title{
Acute Promyelocytic Leukaemia
}

\author{
Sah KP1', Bhattarai S²
}

\begin{abstract}
Acute promyelocytic leukaemia (APML) is the most malignant form of acute leukaemia, relatively uncommon in children, rapidly fatal if untreated and several developments have paved the way to make this disease curable. We report a first case to our knowledge in Nepal in a 12 years old boy who was diagnosed as APML and treated with all trans retinoic acid (ATRA) 14 years back and has been free from disease till date.
\end{abstract}

Key words: APML, Retinoic acid syndrome, ATRA.

\section{Introduction}

$A_{i n}^{\mathrm{c}}$ cute myeloid Leukaemia represents $15 \%-20 \%$ of all leukaemia in children less than 14 years of age with Acute Leukaemia constituting $30 \%$ of all childhood malignancies. Literature has shown that estimated incidence of childhood AML is 5-7 per million people per year and the frequency remains static throughout childhood 1 . As a special entity, APML was first described in 1957 by a Swedish author, Hillestad, when he reported three patients characterized by very rapid fatal course of only a few weeks duration ${ }^{2}$. Acute Promyelocytic Leukaemia is a specific type of acute myeloid leukemic (AML) characterized by the morphology of blast cells; by t (15:17) translocation, which fuses the PML gene on chromosome 15 to the retinoic acid receptor (RAR) a gene on chromosome 17; and by specific coagulopathy ${ }^{3}$. There is arrest of maturation at the promyelocytic stage of myeloid cell development ${ }^{4}$. A WBC:20,000/ cumm has been associated with a better prognosis, and a WBC count of 100,000 /cumm has been linked to an unfavourable outcome ${ }^{5}$. Since the first description of acute promyelocytic leukaemia (APML) in 1957 as the most malignant form of acute leukaemia, several developments have paved the way to make this disease curable. Therapy of APML was pioneered by Bernard et al in 1973 with demonstration of striking sensitivity to daunorubicin. Single agent daunorubicin or idarubicin or combination with anthracyclines or cytarabine were used. Incorporation of all-trans retinoic acid (ATRA) was a revolutionary contribution of the Shanghai group in 1988. More recently, arsenic trioxide (ATO) has been included in the list of active drugs in APML, being perhaps the most active single agent ${ }^{6}$. Some authors recommend ATO as a second line drug ${ }^{7}$.

\section{The Case}

A 12 years old male child was referred to Kanti Children's
${ }^{1}$ Dr. Kailash Prasad Sah, MBBS. MD. Senior Consultant Paediatric Oncologist, ${ }^{2} \mathrm{Dr}$. Susan Bhattarai, MBBS. MD. Paediatrician. Both from the Kanti Children's Hospital, Maharajgunj, Kathmandu, Nepal.

\section{Address for correspondence \\ Dr. Kailash Prasad Sah \\ E-mail: kailashah11@gmail.com}

\section{How to cite}

Sah KP, Bhattarai S. Acute Promyelocytic Leukaemia. J Nepal Paediatr Soc 2017;37(3):270-272.

doi: http://dx.doi.org/10.3126/jnps.v37i3.18553

This work is licensed under a Creative Commons Attribution 3.0 License.

\section{(c) (i)}


Hospital on $30^{\text {th }}$ August 2003 for further workup and management of pancytopenia. He had history of fever for three months along with weakness and dizziness for the same duration. He had history of repeated blood transfusions. On examination he was pale, mildly icteric and had bilateral mild pitting oedema. There was no lymphadenopathy and organomegaly. Other systems were unremarkable. Investigations done in other hospital outside were $\mathrm{Hb}: 7.8 \mathrm{gm} \%$, TLC:5800/cumm (N:66\%, L:33\%, E:1\%), Platelets:262,000/cumm, Serum Bilirubin (T:2.2 mg\%, D:0.9 mg\%), SGPT:10 U/L, SGOT:11 U/L. HIV and HBsAg were non-reactive, malarial parasite was not detected, Urine showed pus cells 4-5/HPF and culture showed S. pyogens, USG of abdomen and pelvis was normal. Repeated investigation after two days showed TLC: $2200 /$ cumm (N:48\%, L:50\%, E:2\%).

Investigations were repeated in our hospital which showed $\mathrm{Hb}$ : $5.8 \mathrm{gm} \%$, TLC: 30,800/cumm, (Promyelocytes: 32\%), Platelets:22,000/cumm and peripheral blood smear showed increased WBC with abnormal promyelocytes with multiple Auer rods (AMLM3). Bone marrow aspiration and biopsy was consistent with AML: M3. Chest X-ray, ECG, and ECHO study were normal. Cytogenetics and flow cytometry were not done due to unavailability of the test and financial reason.

Induction with ATRA was started on $9^{\text {th }}$ September 2003 at dose of $45 \mathrm{mg} / \mathrm{square}$ meter. Bone marrow study done on $28^{\text {th }}$ day showed remission. He developed Retinoic Acid syndrome which was managed symptomatically. ATRA was given total for 90 days. Bone marrow aspiration was done on 30th December 2003 which showed remission. Consolidation was started from $2^{\text {nd }}$ Jan, 2004. He received consolidation $1^{\text {st }}$ cycle consisting of Inj. Daunorubicin $40 \mathrm{mg} / \mathrm{square}$ meter for two consecutive days and ATRA 45mg/square meter for 21 days in a month for total of six months. Bone marrow examination done on $6^{\text {th }}$ June 2004 showed remission. Then he completed maintenance protocol of oral 6MP
$50 \mathrm{mg} \mathrm{HS}$, MTX 15mg/square meter once a week and ATRA $45 \mathrm{mg} / \mathrm{m}^{2}$ for first 15 days of each 90 days cycle for total of two years. Presently he is under regular follow up and is free of disease.

\section{Discussion}

APML is a specific type of acute myeloid leukaemia (AML) characterized by the morphology of blast cells by $t(15 ; 17)$ translocation which fuses the PML gene on chromosome 15 to the retinoic acid receptor (RAR), a gene on chromosome 17 and by specific coagulopathy. Until recently, combination chemotherapy with anthracycline, cytosine arabinoside (Ara-C) was the only treatment of APML, with complete remission (CR) in $65 \%$ to $80 \%$ of newly diagnosed cases $^{8}$. The remaining patients suffered early death, mainly from bleeding due to worsening of coagulopathy or resistance to CT. $50 \%$ to $65 \%$ of the patients who achieved CR subsequently relapsed, and $30 \%$ to $40 \%$ survived at two years. ATRA differentiates abnormal promyelocytes into mature granulocytes in APML and induced CR in $80 \%$ to $90 \%$ of newly diagnosed and first relapsing APML ${ }^{9}$. ATRA rapidly improved coagulopathy without inducing aplasia. However, in $15 \%$ to $25 \%$ of the patients, it is associated with an ATRA syndrome that generally occurred with a rapid increase in white blood cells and often had a fatal outcome. Treatment must begin on the day of diagnosis and the use of daunorubicin, a non- cycle- active drug capable of producing rapid aplasia of bone marrow, seems to be crucial ${ }^{10}$. Despite limitations in supportive care in our setting, our patient was well taken care of and this patient did well despite lack of adequate treatment experiences in our setting.

\section{Conclusion}

In spite of rarity of the disease and limitations in diagnostics and supportive care, patients can be cured provided they are referred to higher centres on time.

\section{References}

1. Fadoo Z, Mushtaq N, Alvi S, Ali M. Acute myeloid leukaemia in children: experience at a tertiary care facility of Pakistan. J Pak Med Assoc 2012;62(2):1258.

2. Wang Z-Y, Chen Z. Acute promyelocytic leukemia: from highly fatal to highly curable. Blood 2008;111(5):250515. DOI: $10.1182 /$ blood-2007-07-102798.

3. Fenaux P, Chastang C, Chevret S, Sanz M, Dombret $H$, Archimbaud E, et al. A randomized comparison of all transretinoic acid (ATRA) followed by

chemotherapy and ATRA plus chemotherapy and the role of maintenance therapy in newly diagnosed acute promyelocytic leukemia. The European APL Group. Blood 1999;94(4):1192-200.

4. Soignet SL, Maslak P, Wang ZG, Jhanwar S, Calleja E, Dardashti LJ, et al. Complete remission after treatment of acute promyelocytic leukemia with arsenic trioxide. N Eng J Med 1998;339(19):1341-8. DOI: 10.1056/ NEJM19981105339.

5. Meshinchi S, Arceci RJ. Prognostic factors and riskbased therapy in pediatric acute myeloid leukemia. Oncologist 2007;12(3):341-55. DOI: 10.1634/ theoncologist.12-3-341 
6. Sanz MA. Treatment of acute promyelocytic leukemia. Hematology Am Soc Hematol Educ Program. 2006:147-55. DOI: 10.1182/asheducation-2006.1.147

7. Shen ZX, Chen GQ, Ni JH, Li XS, Xiong SM, Qiu QY, et al. Use of arsenic trioxide (As2O3) in the treatment of acute promyelocytic leukemia (APL): II. Clinical efficacy and pharmacokinetics in relapsed patients. Blood 1997;89(9):3354-60.

8. P Fenaux SC, A Guerci, N Fegueux, H Dombret, $X$ Thomas, M Sanz, H Link, F Maloisel, C Gardin, D Bordessoule, A-M Stoppa AS, P Muus, H Wandt, P
Mineur, JA Whittaker, M Fey, M-T Daniel, S Castaigne and $L$ Degos, for the, group EA. Long-term follow-up confirms the benefit of all-trans retinoic acid in acute promyelocytic leukemia. Leukemia 2000;14:1371-8.

9. Pierre Fenaux MCLD, Sylvie Castaigne. Effect of All Transretinoic Acid in Newly Diagnosed Acute Promyelocytic Leukemia. Results of a Multicenter Randomized Trial Blood 1993;82(11):3241-9.

10. Goldman JM. Acute promyelocytic leukaemia. Brit Med J 1974;1(5904):380-2. 